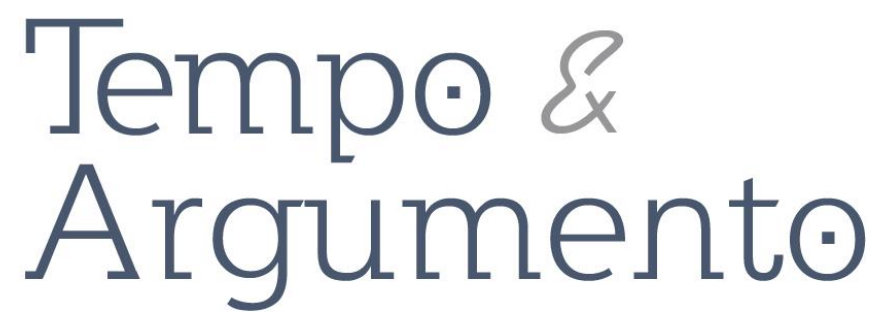

\title{
Museus e identidades no tempo presente
}

\begin{abstract}
Resumo
Pretende-se, aqui, levantar algumas discussões sobre o fazer História do Tempo Presente, com o intuito de dialogar com um fato marcante acontecido em Porto Alegre, no Rio Grande do Sul: o fechamento precoce da exposição Queermuseu - Cartografias da Diferença na Arte, com mais de 270 obras de arte, instalada no Santander Cultural. O grupo de pessoas que pediu o encerramento da exposição reivindicou pura e simplesmente a supressão do seu objeto de desgosto em "arena pública", parecendo ser a nova forma que assume a censura em nosso tempo recente: não mais a decisão do Estado, mas o clamor mais ou menos anônimo, reverberado pelas redes sociais digitais, contra a mera existência do que desagrada uma parcela da sociedade, no caso, as obras com temas sobre a diversidade, corpo e religião.
\end{abstract}

Palavras-chave: História do Tempo Presente. Artes Visuais. Arte Contemporânea. Queer.

\author{
Aline do Carmo \\ Doutoranda em História na Universidade de \\ Passo Fundo (UPF). Professora convidada \\ Universidade de Passo Fundo (UPF). \\ Passo Fundo - RS - BRASIL \\ acarmo@upf.br \\ orcid.org/0000-0002-9036-1795
}

\section{Maria Goreti Baptista Betencourt}

Doutoranda em História na Universidade de Passo Fundo (UPF). Professora da Universidade de Passo Fundo (UPF). Passo Fundo - RS - BRASIL bett@upf.br orcid.org/0000-0002-4900-2598

\section{Para citar este artigo:}

CARMO, Aline do; BETENCOURT, Maria Goreti Baptista. Museus e identidades no tempo presente. Tempo e Argumento, Florianópolis, v. 11, n. 26, p. 486 - 507, jan./abr. 2019. 


\title{
Museums and identities in the present time
}

\begin{abstract}
It is intended here to raise some discussions about the making of Present Time History, in order to dialogue with a remarkable event that took place in Porto Alegre, Rio Grande do Sul: the early closure of the exhibition, Queermuseu - Cartografias da Diferença na Arte, with more than 270 works of art, installed in Santander Cultural. The group of people who called for the closing of the exhibition simply claimed to suppress their object of disgust in the "public arena," appearing to be the new form of censorship in our recent time: no longer the State decision, but the a clamor more or less anonymous, reverberated by digital social networks, against the mere existence of what dislikes a certain majority, in this case, works with themes on diversity, body and religion.
\end{abstract}

Keywords: History of the Present Time. Visual Arts. Contemporary Art. Queer.

A arte reflete uma necessidade de mudança que é inerente à natureza humana; ela não se fixa apenas num tempo histórico específico, transita por diferentes períodos e movimentos artísticos, do clássico ao pós-moderno. O foco da arte geralmente é um olhar do que se opera nos circuitos socio-culturais em que os artistas estão inseridos, afinal a arte é feita por pessoas, e estas vivenciam seu tempo presente, e este ciclo pode ser agradável, ou não. O artista materializa o subjetivo.

Neste artigo, vamos pensar o fato do fechamento de uma exposição como representação dessa história do recente, proposta por Larrosa (2004) investigador deste campo historiográfico, que traz um pressuposto epistemológico dessa metodologia marcada na subjetividade. Algumas pessoas, ofendidas com o conceito e o teor de certas 
obras, vistas distorcidamente e fora do contexto geral da exposição que tratava sobre comportamento, liberdade e diversidade - exigiram do Santander Cultural de Porto Alegre, o fechamento da Queermuseu - Cartografias da Diferença na Arte.

Ao utilizarmos a figura do ensaio como representação dessa história do recente, e do papel do ensaísta proposto por Larrosa (2004), como representação do investigador desse campo, sinalizamos para o que entendemos ser o pressuposto epistemológico mais relevante deste módulo historiográfico: se marcar pela e na subjetividade, e especialmente, ser uma história de nós mesmos, ainda que outros tipos de história em alguma medida também o sejam. Jorge Larrosa afirmou que o ensaio se caracterizaria pela sua constante problematização, "uma escrita no presente" e tendo como finalidade dar forma a uma experiência desse presente.

Pensamos que, diante da demanda intensa de muitas pessoas ávidas por uma inteligibilidade de si e do entorno, o historiador do novo deve identificar um instrumento que possibilite a análise dos fatos. Jean-Pierre Rioux, questionaria a respeito disso:

[...] o presente é objeto da história? [...] Avançando um pouco a reflexão, percebe-se que essa dúvida remete a uma inquietação propriamente filosófica: o presente tem sua chance diante de uma longa duração que parece ser - toda a obra de um Fernand Braudel foi construída em cima desse "parece" - a verdadeira modulação e a respiração vital do devir humano? (RIOUX, 1999, p. 40)

O fato, a política e a narrativa são as "voltas" historiográficas para a história do tempo presente. A política apareceu como importante ponto nas pesquisas sobre o atual, principalmente com o trabalho de René Rémond (1994), escritor que dialogou com a segunda geração dos Annales, trazendo a questão da política e do contemporâneo para a construção da história.

Parece-nos que a polêmica gerada pelo fenômeno Queermuseu se compreende pelo fato de que a exposição não se ajustava aos parâmetros normais de mostras convencionais, talvez, mais formalistas. A exposição tratava de questões de gênero e diversidade em um momento em que a sociedade brasileira pode estar se encaminhando para um acirramento em direção à direita e à ultradireita política. Sobre isso, Cocchiarale 
(2006) questiona: "Quem tem medo da arte contemporânea?" Muitos. A maioria, segundo ele, diz não a entender, por achá-la estranha àquilo que consideram arte. Outros, ainda que com conhecimento de causa, seja por conservadorismo, seja por preferirem a arte clássica ou por sua fidelidade teórica (paixão, na verdade) à arte contemporânea. O autor nos traz uma resposta sobre a questão aqui levantada:

O que está em questão é a busca ansiosa pela explicação verbal de obras reais e concretas, como se sem a palavra fosse-nos impossível entendêlas. A explicação assassina a fruição estética, já que ao reduzir a obra a uma explicação mata sua riqueza polissêmica e ambígua, direcionando-a num sentido unívoco. (COCCHIARALE, 2006, p. 6)

O artista contemporâneo parece nos convocar para um jogo no qual as regras não são lineares, mas desdobradas em redes de relações possíveis, ou não, de serem estabelecidas. Se a arte contemporânea dá medo é por ser abrangente demais e muito próxima da vida.

Parece que o que ocorreu nas manifestações para o fechamento da exposição de arte em Porto Alegre, que celebrava a diversidade, talvez, foi o obscurantismo de um grupo de pessoas que pensaram que detinham uma "régua" ética e estética, para dizer o que é ou não arte proba nos dias atuais. Gaudêncio Fidelis, curador da exposição, cita um dos sentidos da arte, "A arte mais uma vez tomava para si o protagonismo dos debates sobre comportamento, sexualidade, diversidade e pluralidade como ninguém sequer poderia supor." (FIDELIS, 2018, p.40)

Nesse espaço, parece-nos importante notar a questão política influenciando o fechamento da exposição em Porto Alegre/RS, já que todo o tumulto em torno de obras de arte "ofensivas" fica acobertado nos enredos políticos de um país prestes a ter novas eleições presidenciais em 2018. Cultura e política cruzam-se nos estudos que tratam do presente, o que enriquece os resultados das pesquisas historiográficas e oferece várias opções para os historiadores, que não se prendem a certas amarras impostas pela prática historiográfica, como o afastamento temporal do objeto de estudo, e recorrem a fontes variadas para a produção de suas análises. 
Para entendermos um pouco mais profundamente o porquê dos debates acerca da exposição, vamos ao significado do nome Queer. Os primeiros registros do uso do termo são do século 16. Mas o significado da palavra foi subvertido com o tempo. Este conceito artístico reúne obras criadas entre 1861 e 1967, antes mesmo de o termo inglês “queer" passar a ser aplicado de forma generalizada não só para gays, mas para quaisquer indivíduos que não são heterossexuais ou cisgênero (pessoa que se identifica com o sexo biológico com o qual nasceu).

Em 1990 foram publicadas duas importantes obras que contribuiriam para a adoção desse uso mais amplo da palavra: Gender Trouble, da filósofa Judith Butler, que ganhou versão em português como "Problemas de Gênero", e Epistemology of the Closet, de Eve Kosofsky Sedgwick. As autoras estão entre as pioneiras da queer theory, uma linha de pensamento que analisa atos sexuais e identidades no geral como algo múltiplo e culturalmente construído. A partir da década de 1990, essa teoria passa a exercer influência no mundo todo, inclusive no Brasil, o que contribuiu para que o termo passasse a ser adotado também no país.

A aceleração do mundo atual, o poder da mídia, as redes sociais digitais etc., mudaram as relações culturais, políticas, sociais e econômicas que eram características do mundo pós-guerra, provocando assim, a possibilidade de produção acelerada de informações. Além de revolucionar a comunicação entre as pessoas, aproximam por meios digitais territórios fisicamente distantes e geram um levante, como o caso do Queermuseu no Rio Grande do Sul, em setembro de 2017. Gaudêncio Fidelis comenta sobre pesquisa realizada após o fechamento da exposição:

[...] acabamos de descobrir, por exemplo, que foram colocados em ação robôs e perfis fakes para impulsionar ataques à exposição Queermuseu, como constatou a recente pesquisa realizada pela Diretoria de Análise de Políticas Públicas da Fundação Getúlio Vargas (FGV/DAPP), derrubando uma das maiores farsas dessa narrativa. (FIDELIS, 2018, p. 41)

Manifestar opiniões é um direito inalienável. Parece ser procedente uma pessoa não gostar de uma obra de arte; por vezes são obras realmente ruins, tolas, mas não importa, pois a arte visual está direcionada à questão do humano; é uma leitura e uma 
percepção do simbólico, sendo que a partir desta questão consegue-se entender um pouco mais do desenvolvimento da própria cultura através da arte.

Na manhã de sábado (9 de setembro de 2017), a página do MBL (Movimento Brasil Livre) no Facebook compartilhou um texto publicado no site Jornal Livre com o título "Santander Cultural promove pornografia e até pedofilia com base na Lei de Incentivo à Cultura". Durante os dias que seguiram, diversos perfis de grupos e pessoas que simpatizam com o MBL, aderiram ao protesto compartilhando imagens e vídeos da exposição nas redes pedindo o fechamento da mostra e também o boicote ao banco Santander. O MBL é uma organização não governamental de ativismo político, segundo o site oficial do movimento (mbl.org.br). A mobilização desse grupo incluiu blogues e páginas de cunho religioso, católicas e evangélicas.

De acordo com as queixas do grupo, os trabalhos da mostra seriam ofensivos à moral e à religião cristã. A página do $\mathrm{MBL}$ no Facebook publicou diversos posts em torno do assunto, alguns com milhares de curtidas. O conteúdo das postagens alega que a mostra usou dinheiro público "para promover pedofilia e zoofilia". A menção ao dinheiro público se deve ao fato da exposição ter sido contemplada pela Lei Rouanet, proporcionando alívio fiscal ao Santander no valor de $\mathrm{R} \$ 800 \mathrm{mil}$.

O Santander Cultural, situado em Porto Alegre, cancelou no dia 10 de setembro de 2017 a exposição Queermuseu - Cartografias da Diferença na Arte. A mostra estava prevista para permanecer em cartaz até o dia 8 de outubro. Na época em que a exposição foi anunciada, o Santander informava que "valoriza a diversidade e investe em sua unidade de cultura no Sul do País para que ela seja contemporânea, plural e criativa". A mostra foi encerrada um mês antes do previsto.

Com curadoria de Gaudêncio Fidelis, reunia 270 trabalhos de 85 artistas que abordavam questões de gênero e de diversidade sexual. As obras - percorrem o período histórico de meados do século XX até os dias de hoje, sendo que entre os artistas estão nomes importantes do cenário brasileiro das artes visuais como: Alfredo Volpi, Adriana Varejão, Cândido Portinari, Clóvis Graciano, Fernando Baril, Hudinilson Jr., Lygia Clark, Leonilson e Yuri Firmesa. 
O conteúdo da exposição gerou revolta nas redes sociais, segundo o grupo de pessoas que formam o MBL, "pelo bizarro conteúdo sexual da amostra, inapropriado ao público infantil em idade escolar que frequentava o espaço. Para completar, foi descoberto que o banco havia sido beneficiário de $\mathrm{R} \$ 800$ mil captados pela Lei Rouanet para a realização do evento", segundo Luiz Guilherme Medeiros, Diretor do Instituto Liberal do Centro-Oeste, em 12/09/2017 (www.huffpostbrasil.com).

Conforme o diretor desse instituto, após a imensa repercussão negativa, o Banco Santander decidiu encerrar a exposição e emitiu uma nota de desculpas pelo ocorrido. Os defensores da mostra, contrariados pela pressão social ter feito o banco reconsiderar sua atitude, rapidamente passaram a rotular os indignados como "fascistas" e "censores".

A decisão da instituição foi uma resposta à onda de protestos que ocorreu nas redes sociais. Pessoas e grupos organizados consideraram a mostra ofensiva, destacando que algumas obras representavam "blasfêmia" e faziam "apologia à zoofilia e pedofilia".

Em nota oficial, o Santander justificou o cancelamento, via rede social, na página oficial do banco no Facebook, em 11 de setembro de 2017; segue parte do texto:

Nos últimos dias, recebemos diversas manifestações críticas sobre a exposição Queermuseu - Cartografias da Diferença na Arte Brasileira. Pedimos sinceras desculpas a todos os que se sentiram ofendidos por alguma obra que fazia parte da mostra. O objetivo do Santander Cultural é incentivar as artes e promover o debate sobre as grandes questões do mundo contemporâneo, e não gerar qualquer tipo de desrespeito e discórdia (...) Ouvimos as manifestações e entendemos que algumas das obras da exposição Queermuseu desrespeitavam símbolos, crenças e pessoas, o que não está em linha com a nossa visão de mundo. Quando a arte não é capaz de gerar inclusão e reflexão positiva, perde seu propósito maior, que é elevar a condição humana. (REPRODUÇÃO FACEBOOK Santander Oficial)

Por outro lado, o curador da Queermuseu, Gaudêncio Fidelis, disse que foi pego de surpresa pelo cancelamento da mostra: "Essa decisão foi unilateral do Santander. Não fui consultado em nenhum momento sobre isso, e ninguém do Santander entrou em contato comigo. Fiquei sabendo do cancelamento por um grupo de Whatsapp"', disse

\footnotetext{
${ }^{1}$ Software para smartphones utilizado para troca de mensagens de texto instantâneas, além de vídeos, fotos e áudios através de uma conexão com a internet.
} 
(www.gauchazh.clicrbs.com.br). Com experiência de curador de duas bienais do Mercosul, Fidelis disse que nunca tinha visto algo parecido com essa decisão de encerramento da exposição.

\section{As obras estigmatizadas}

As manifestações foram organizadas e se debruçaram sobre algumas obras muito específicas, que não mostram a verdadeira dimensão da exposição. Entre as imagens mais compartilhadas na rede social Facebook $^{2}$ estavam a reprodução de Jesus Cristo (Figura 01) com múltiplos braços, o desenho de uma pessoa praticando sexo com um animal (Figura 02) e desenhos de crianças (Figura 03) sob as frases: "Criança viada travesti da lambada" e "Criança viada deusa das águas".

Em uma das obras mais incompreendidas (Figura 01), Jesus é retratado exatamente como todos estão acostumados a vê-lo: crucificado. Gaudêncio Fidelis, no texto do catálogo da exposição, comenta a obra de forma contemporânea:

As inúmeras pernas e braços da figura reverberam pela superfície da pintura, exibindo objetos de toda a ordem nas mãos e nos pés, muitos deles relacionados direta ou indiretamente à história da arte e à cultura pop: elementos da Guernica, de Picasso, por exemplo, são seguradas por duas mãos da figura; no aparador, uma espécie de altar adornado por uma falsa renda de plástico colada com fita adesiva, sobre o qual repousa uma pintura de Marilyn Monroe, uma garrafa de Coca-Cola, exaustivamente tematizada ao longo da história da arte, uma lata de sopas Campbells. (FIDELIS, 2017, p. 35)

Os inúmeros braços com que foi representado, como diz o título da obra, “Cruzando Jesus Cristo com Deusa Shiva”, são uma associação com a divindade hindu. A obra traz o símbolo máximo do cristianismo cercado por referências pop. A peça em

\footnotetext{
2 É uma rede social lançada em 2004. Fundado por Mark Zuckerberg, Eduardo Saverin, Andrew McCollum, Dustin Moskovitz e Chris Hughes, estudantes da Universidade Harvard. Inicialmente, a adesão ao Facebook era restrita apenas para estudantes da Universidade de Harvard, e logo foi a muitas universidades individuais. O Facebook é gratuito para os usuários e gera receita proveniente de publicidade, incluindo banners e grupos patrocinados. Os usuários criam perfis que contêm fotos e listas de interesses pessoais, trocando mensagens privadas e públicas entre si e participantes de grupos de amigos. A visualização de dados detalhados dos membros é restrita para membros de uma mesma rede ou amigos confirmados, ou pode ser livre para qualquer um.
} 
acrílico, do porto-alegrense Fernando Baril, é de 1996, e somente em 2017 gerou toda essa perturbação. A arquidiocese de Porto Alegre, em sua página oficial no Facebook, declarou enfaticamente: "Em tempos de terrorismo e intolerância, não se constroem pontes com agressão e desrespeito pelo que é mais íntimo e sagrado no outro: sua fé e seu corpo".

Figura 01

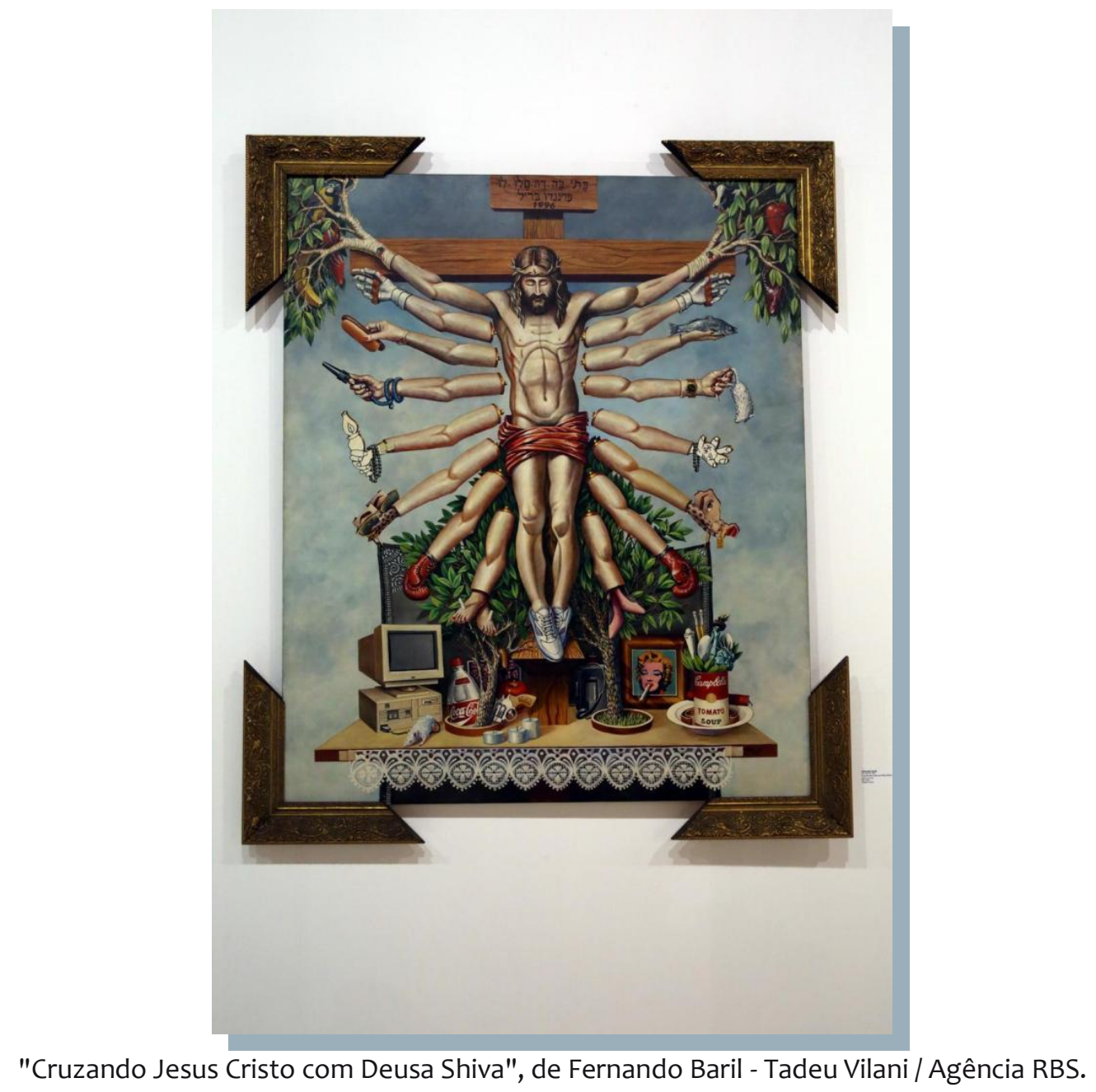

A próxima obra que gerou o movimento pelo fechamento da exposição, "Cenas de Interior II" (Figura 02), pintada por Adriana Varejão em 1994, representa as marcas de um pergaminho guardado. As cenas em que dois homens se relacionam com uma cabra e dois homens brancos se relacionam com um homem negro foram inspiradas em histórias de iniciação sexual que a artista escutou em Alagoas. Sobre essa obra Gaudêncio fala: 
Ela mostra o avanço da pintura brasileira como manifestação crítica diante do processo de colonização do país. Trata-se de uma pintura que cobre um considerável território na confluência entre sexualidade e história, revirando (literalmente) as hierarquias de raça, influências, miscigenação, mestiçagem e "canibalismo queer"... ela perturba as relações verticais e eventualmente as horizontaliza - com as figuras deitadas ou reclinadas por meio de relações sexuais heterossexuais, homossexuais que introduzem através da pintura. Uma variedade de tipos comunga de relações sexuais nessa pintura (duas figuras femininas japonesas, uma figura japonesa e um negro, dois homens brancos e um negro, duas figuras masculinas brancas indistintas com uma cabra). Passado e presente articulam-se nas diversas narrativas, acentuada pelos variados planos que desdobram o tempo de modo que tenhamos uma nítida visão de uma perturbação no drama sexual que se desenrola através da historia. (FIDELIS, 2017, p. 40)

Figura 02

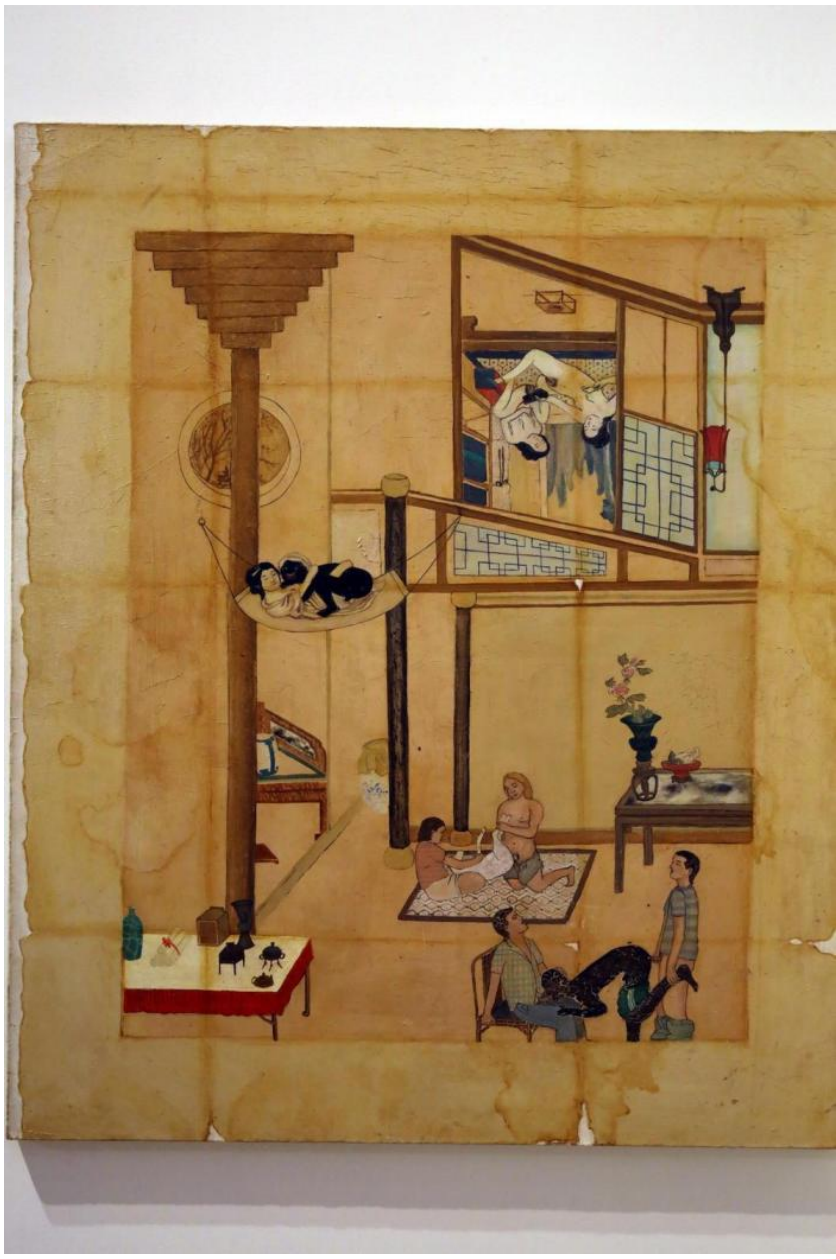

"Cenas do Interior II", de Adriana Varejão - Tadeu Vilani / Agência RBS. 
Outra obra que gerou o levante contra a exposição de arte, "Travesti da Lambada e Deusa das Águas" (Figura 03), criada por Bia Leite em 2013, tem como objetivo combater o bullying. Fidelis afirma que as obras de Bia tratam das mazelas que podem acompanhar a infância das pessoas:

As duas obras de Bia Leite (da serie Born to Ahazar) tratam do universo queer infantil e das mazelas da infância, como o bullying, a violência verbal e exploração psicológica. Bia talvez seja uma das poucas artistas brasileiras a enfrentar com desenvoltura e coragem esse tema tabu, que é a homossexualidade na infância e o portentoso sofrimento que crianças atravessam na fase escolar e no início da adolescência. (FIDELIS, 2017, p. 48)

Segundo Fidelis (2017), o próprio título é “emblemático da radical estratégia de 'retornar' simbolicamente uma agressão ao universo social do agressor, transformando o preconceito em experiência de alteridade”. Além disso, o curador entende que o termo "viada”, no feminino, ao lado de "criança", "dessexualiza o xingamento e empodera o sujeito". "Essas imagens afirmativas de crianças falando em sua própria voz são uma profunda (e contemporânea) afirmação da expressão de gênero e liberdade criativa", explica Fidelis. A exposição contava com obras de diferentes artistas e épocas de produção, entre pinturas, gravuras, fotografias, vídeos, colagens, esculturas e cerâmicas.

Figura 03

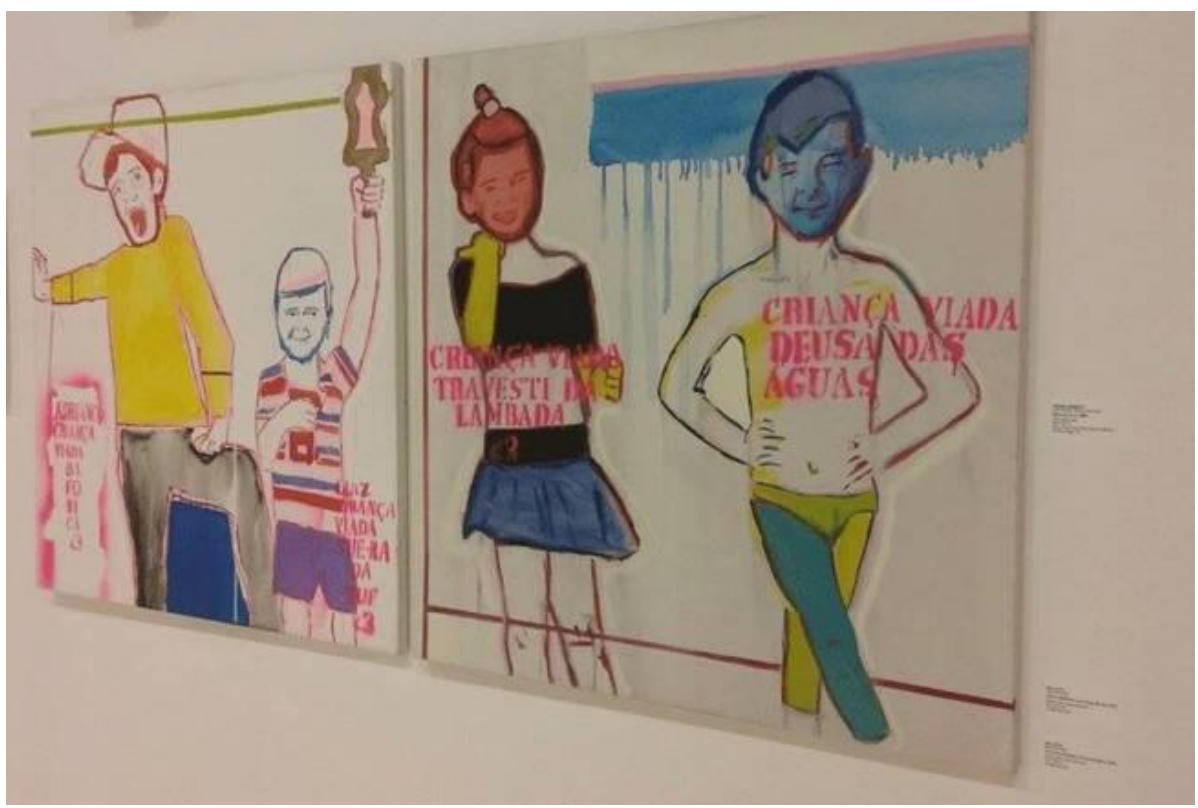

"Travesti da Lambada e Deusa das Águas", de Bia Leite - Divulgação / Santander Cultural. 
Detalhe pertinente é o texto publicado pelo Santander na abertura da exposição, em 15 de agosto de 2017, no qual informava que se tratava de uma iniciativa inédita que explorava a diversidade de expressão de gênero e a diferença na arte e na cultura em períodos diversos. O banco afirmou que valorizava a diversidade e investia em sua unidade de cultura no Sul do País para que ela fosse contemporânea, plural e criativa.

Atacar a liberdade de expressão parece explicitar um "limitar e impedir" que artistas, curadores e instituições se valham da arte como um modo de expressar e vivenciar suas épocas e suas histórias presentes. Pode parecer uma clara política de retrocesso face ao processo histórico que implantou um estado democrático de direito no Brasil. A arte nos parece um exercício contínuo de transgressão, principalmente a partir das vanguardas do começo do século 20. Isso dá a ela uma importância social muito grande porque, ao transgredir, ela aponta para novos caminhos e para soluções que ainda não tínhamos imaginado, para problemas que muitas vezes sequer conhecíamos. No entanto, esse modo de "freio" que a arte sofreu nesse período, não é novidade na história da arte. Vejamos o governo do monge Savonarola no renascimento italiano (século 14 ao 16), quando várias obras foram queimadas por não atenderem ao ditames do momento, ou a quantidade de livros queimados pelos nazistas durante a Segunda Guerra, entre tantos outros exemplos.

Os argumentos utilizados pelos "censores" da exposição evidenciaram essencialmente a questão do corpo na arte e como ele foi representado em tais obras, assim parece-nos pertinente um referencial que nos diga como o corpo humano foi utilizado ao longo da história da arte.

\section{O corpo na arte}

O corpo sempre exerceu uma fascinação no sujeito humano. Em várias épocas históricas as relações com o corpo foram de uma ou outra forma vivenciadas e até exploradas. Porém, mesmo que objeto de interesse da ciência, o espaço por excelência da visualidade do corpo acabou por ser circunscrito no campo da arte visual. 
Seja porque esse corpo projetado encontrava eco em representações simbólicas divinizadas, seja porque representavam relações estéticas e epistêmicas. O certo é que o corpo humano sempre esteve presente no construto da arte.

Henri Zerner (2008 p.103), em História do Corpo 2, diz que "O corpo sempre exerceu um papel capital na arte do ocidente". O Renascimento redescobre o corpo coberto da Idade Média com grande excitação. Os grandes nus mitologizados ou não, as descobertas anatômicas de Leonardo da Vinci e o poderoso vigor dos corpos representados por Michelangelo, marcam um apogeu importante do olhar sobre o corpo humano, "a observação e a coisa observada se combinam para fazer do corpo um lugar privilegiado da imaginação."

Assim de acordo com Zerner (2008), o artista moderno é o herdeiro dessa tradição grega sobreposta à carga recebida da tradição judaica também incorporada pelo cristianismo. Ou seja: ao mesmo tempo em que o corpo é um microcosmo do mundo, é também o espelhamento da imagem divina.

Esse confronto entre o corpo sexualizado e o corpo espiritualizado foi disputado em diferentes correntes do pensamento humano.

Em diversos momentos da pintura histórica, um corpo nu, que poderia gerar uma reação mais visceral relacionada à sexualidade explícita, vinha encoberto por um tema histórico ou mitológico permitindo que sua fruição ficasse liberta do "pecado" da luxúria; assim, sublimado em um espaço contemplativo simbólico, essa forma de apresentação do nu livra o fruidor de uma sensação de lascívia primitiva, transformando-o em um fruidor sofisticado e educado.

A questão do erotismo nem sempre teve o formato que vemos hoje. Del Priore (2011) descreve a relação de sensualidade e erotismo do renascimento como um território ligado muito mais à beleza em si e ao humanismo crescente do que à vergonha ou pudor. Em algum momento, essa nudez estava vinculada à inocência de um lado, (sem pelos pubianos representados) e à pobreza de outro, pobreza essa relacionada à falta de conhecimento, artefatos, bens em geral. Ao contrário da ostentação oriental, as americanas eram pobres e dessensualizadas. 
Mas também, segundo a autora, com os jesuítas, apareceram as relações entre luxúria e nudez. Era preciso cobrir os corpos dos indígenas porque, especialmente as mulheres, além de andarem nuas não se negavam a ninguém. Mary Del Priori fala sobre o nu na história:

\begin{abstract}
Mas que significado teria o nu, na Idade Moderna? A nudez era erótica? Havia, então, uma grande diferença entre nudez e nu. A nudez se referia àqueles que fossem despojados de suas vestes. $O$ nu remetia não à imagem de um corpo transido e sem defesa, mas ao corpo equilibrado e seguro de si mesmo. O vocábulo foi incorporado, no século XVIII, às academias de ciências artísticas, onde a pintura e a escultura faziam do nu o motivo essencial de suas obras. (DEL PRIORI, 2011, p. 12)
\end{abstract}

Quando falamos do corpo na arte e quando falamos do corpo sexualizado na arte também encontramos interessantes contrapontos.

A nudez esteve presente na Antiguidade Clássica como uma forma de valorização do humano em relação à imagem do divino. Assim, não era um corpo sexual que se via, senão a representação idealizada da perfeição divina travestida no corpo humano nu e jovem. E essa ideia de corpo perfeito podia ser reproduzida na própria forma como os gregos se viam e construíam sua cultura.

O Renascimento e o Neoclassicismo reverberam essas mesmas ideias em que o corpo representado não é o corpo real. Esses corpos idealmente belos ficavam dessexualizados ou com seu erotismo encoberto pela temática, pela metáfora e, portanto, pela distância entre o referente e a representação.

No século XIX, essa distância se reduz com a tentativa de aproximar a arte da vida em si mesma. O ponto de choque talvez tenha sido o realismo de Gustave Courbet, especialmente no quadro L'origine du monde (A origem do mundo), um retrato realista de um torso feminino, dos seios às coxas, em uma representação praticamente clínica dos órgãos genitais femininos, não depilados (na tradição acadêmica), ou do quadro Le sommeil (O sono), do mesmo autor, que é uma representação dos amores lésbicos. Zerner aponta esse modelo realista de "ver o mundo" de Courbet. 
Courbet é herdeiro legítimo da modernidade concebida por Géricault. Ele mesmo declarou que não se poderia, verdadeiramente, fazer a história, senão a de seu próprio tempo. Mais importante ainda é que a história, essa, não é obra dos heróis e dos governantes, mas de todos e de cada um. Esse programa, aparentemente simples, é de extrema dificuldade e até paradoxal, se, como Courbet, não se renuncia a uma tradição elitista da arte à sua monumentalidade, a sua panóplia de meios de expressão apropriada a uma concepção heróica e idealista da história. (ZERNER, 2008, p. 119)

No final do século XIX, Manet expõe Le déjeuner sur l'herbe (O almoço na relva), onde uma jovem aparece nua entre dois homens vestidos. O clamor contra essa obra se deveu basicamente ao fato de a mulher representada ser uma pessoa da sociedade e não uma deusa. E mesmo o quadro Olympia, que é a representação de uma deusa, foi criticado por parecer muito urbano, moderno, pouco abundante, e por retratar um corpo cuja identidade da modelo poderia ser reconhecida (Victorine Meurand). Esse quadro provoca uma discussão ideológica, um confronto entre a independência e a academia. A Olympia de Manet é muito realista, "verdadeira", e portanto falsa sob o ponto de vista da arte acadêmica, idealizada. A representação sempre é um sistema complexo em si mesmo e que assume um caráter ideológico. Essa afirmação fica patente na análise que Zelner faz sobre a percepção da representação sob o viés fisiológico ou cultural.

Por outro lado, a recepção, ou seja, a maneira como a obra é percebida, depende evidentemente das disposições e dos hábitos visuais do espectador, de seu equipamento mental (razão por que, hoje, se distingue bem a percepção visual, seja o equipamento fisiológico da visão, daquilo que um recente vocábulo anglo-saxão denomina visuality, seja a visão tal como é condicionada pelos hábitos de cultura. (ZERNER, 2008, p. 130)

É importante salientar as questões que envolvem a arte, seus recortes e sua função, contudo, isso nem sempre é uma questão simples. A função está na mercadoria, portanto nas relações econômicas. Entretanto, a arte é também uma mercadoria, quando transformada em bem de consumo e de troca comercial. Esse não é o seu objetivo como meio de expressão mas o que se torna quando tratada como mercadoria. 
Sandra Ramalho e Oliveira diz que:

Existem diversos estudiosos que são contra pensar em arte como fenômeno que tenha "função", pois a reação entre arte e sujeito deveria ser de "pura gratuidade". Outros dizem que o próprio fato de uma imagem "funcionar esteticamente" já é em si, uma utilidade, uma função. O que se observa é que as funções de uma imagem podem mudar, através não só do tempo como também do espaço. E se mudam as funções consequentemente também pode mudar a categoria dessa imagem. (RAMALHO E OLIVEIRA, 2005, p. 23)

Assim, a arte passa por diversas circunstâncias e nela também está impresso aquilo que a torna efetiva. E, em grande medida, está o mundo emocional do sujeito, no modo como este recebe e percebe a expressão artística. Cada período histórico traz seus conceitos culturais embutidos, de onde derivarão tanto a produção quanto a recepção artística. Isso sem falar do próprio mercado de arte que tem suas regras específicas.

É difícil definir o que é arte, mas uma coisa é certa: ela não tem mais obrigatoriamente o compromisso com o belo. No final do século XVIII e início do XIX, já se delineavam discussões acerca da morte da arte, uma vez que esta havia se estandardizado em um processo que se mostrava repetitivo e pouco inovador. A arte moderna, introduzida pelo Impressionismo, traz uma ruptura significativa desse processo, sendo um movimento visto, a princípio, como uma agressão ao mundo da arte, por não seguir convenções técnicas mas sim científicas.

Junto ao Impressionismo, a fotografia se populariza; ela já havia sido criada anteriormente mas passa agora a alastrar-se não apenas pelo mundo científico mas também pelo mundo da arte. Os impressionistas não brigaram com a nova técnica; ao contrário, até tomaram emprestada da fotografia seus recortes de ângulos; no entanto, parecia não fazer mais sentido a arte enquanto modo de apresentação e representação.

Sendo assim, após o Impressionismo, os movimentos que se seguiram em diferentes segmentos começaram a pensar na arte pela arte. Ela passou a ser o objeto de atenção e não necessariamente de expressão da beleza e, nem mesmo, da reprodução da natureza humana, ou não, em seus estados mais inebriantes. 
De certa forma, a arte pós-impressionista e moderna, passou a ser vista com desconfiança pelas pessoas, porém, como objeto perfeito de evocações filosóficas, sociológicas e técnicas em si mesma. O exemplo que Michaud traz deixa claras essas novas relações da arte com seu tempo, especialmente quando faz referências ao contexto sexual.

A confluência da onda de liberdade sexual dos anos 1970 e do refluxo provocado pela SIDA (AIDS) suscita obras onde se misturam obsessão da sexualidade e angústia da morte. $O$ trabalho de Mapplethorpe é um bom exemplo dessa ambivalência existencial. Chega segundo o título de uma exposição de 1994, "o inverno do amor”. Uma só angústia vem envolver o mundo da beleza que se imuniza dessa angústia por um assunto de leveza e provocação. Já se tratou desse homem pós humano, que se esboça na arte. Essa perspectiva pós humana põe em xeque e em crise as certezas em matéria de identidade e de auto certeza, abaladas por outro lado pela descoberta de outras vivências e de outras construções do corpo através dos trabalhos das artistas feministas (Nancy Spero, Judy Chicago, Cindy Sherman, Barbara Kruger) ou das contribuições dos artistas homossexuais e do pensamento queer. (MICHAUD, 2005, p. 562)

Assim, parece interessante trazer o conceito de Heidegger (1999) sobre a arte: o de que ela é feita para que atinjamos a verdade de uma maneira não-convencional. Uma coisa é ler sobre consumismo, a vulgarização do cotidiano, e outra coisa é ver a obra de Andy Warhol, Latas de Sopa Campbell, de 1962. Ambas trazem verdades semelhantes, mas acessíveis de maneiras diferentes.

A atribuição da arte é permitir novas ideias, proporcionar reflexão, imagem e revelar algo do inconsciente coletivo. Para isso ela precisa necessariamente existir no território do inexplorado, do desconhecido, da originalidade e do inominável. Esse território nunca pode ser alcançado se a arte for mantida em um cercado conceitual, dentro do qual está pré-definido o que pode e o que não pode. A arte é sobre o que não sabemos e por isso deve poder ser transgressora, indefinida, incompreendida, subjetiva.

Por esse viés, podemos interpretar o acontecimento do Queermuseu como uma demonstração clara de que, embora o momento histórico desse evento tenha se apresentado na primeira metade do século XXI, e que, ingenuamente, talvez muitos de nós pensássemos que as questões ligadas à sexualidade estivessem pacificadas, obviamente, não foi isso o que a mídia mostrou. Não importa verdadeiramente quantas 
pessoas pensam de uma maneira mais conservadora ou menos. O que o evento demonstrou é que as relações da arte, assim como a política, e mesmo a religião estão como sempre estiveram, entrelaçadas com o background dos sujeitos em seus sistemas socio-culturais. Nesse caso, esse evento em particular esteve sim, atrelado às polarizações que ocorriam, especialmente por conta das futuras eleições que ocorreriam no país em outubro de 2018.

\section{O desfecho da censura nas redes}

Após o fechamento da exposição, no dia 29 de setembro de 2017, o Ministério Público Federal (MPF) do Rio Grande do Sul, em documento enviado ao Santander Cultural, recomendou a reabertura da exposição, pois considerou que as obras não apresentavam qualquer apologia ou incentivo à pedofilia. O Santander não acatou a recomendação, mesmo com o parecer do procurador do Estado, "O precedente do fechamento de uma exposição artística causa um efeito deletério a toda liberdade de expressão artística, trazendo à memória situações perigosas da história da humanidade como os episódios envolvendo a 'Arte Degenerada' (Entartete Kunst), com a destruição de obras na Alemanha durante o período de governo nazista", disse Fabiano de Moraes, procurador regional dos Direitos do Cidadão, no documento.

A mostra fechada contou com 800 mil reais do Santander, abatidos de impostos através da Lei Rouanet. O banco estava ciente do seu conteúdo quando ela foi aprovada, e prometeu devolver o valor ao governo. A Promotoria da Infância e da Juventude, do Ministério Público Estadual, que atua na proteção às crianças, garantiu que não há nenhuma apologia à pedofilia nas obras. "Desde logo, afasto, dessas imagens por si, o aspecto de pedofilia, eis que não contém criança ou adolescente na cena captada ou produzida. Ressalto que não se depreende das imagens, por si, a instigação à prática de ato sexual com o objetivo de satisfazer a lascívia de outrem, elementos fundamentais dos tipos penais do Estatuto da Criança e Adolescente (ECA), antes invocados. Em razão disso, ao menos neste momento, não vislumbro a necessidade de procedimento investigatório criminal”, afirmou o promotor Júlio Almeida em depoimento dado à revista Veja, 2017, Ano 50, n. 38. 
Em nota oficial no site do banco, o Santander pediu "sinceras desculpas" a todos os que se sentiram ofendidos pelas obras e dizia reconhecer que "algumas obras desrespeitavam símbolos, crenças e pessoas". Nos parece claro que nada como a pressão "feroz" das redes sociais digitais para, pode-se dizer, tamanha epifania de conveniência. A pressão do MBL e o marketing da instituição, nos parece, foram os fatos determinantes para fechar as portas da exposição que celebrava a diversidade.

Efetivamente, a História Antiga foi, por muito tempo, o grande assunto dos historiadores. De acordo Hartog (2015), Chateaubriand, dizia-se surpreendido pela história: "Eu escrevia a história antiga, e a história moderna batia à minha porta” (apud Hartog, 2015, p. 133). A história do tempo presente trabalha com a história construída de memórias recentes e, como a memória é algo social, uma narrativa, uma interpretação dos fatos é relevante neste artigo.

Na história do tempo presente, tratamos da história de pessoas vivas, no contexto em que vivem. Este historiador, então, permanece atento aos cenários econômicos (imperialismo), políticos (identificações de gênero, etnia, religião, sexualidade) e socioculturais (direitos humanos) em que os fatos ocorreram para o maior entendimento do conteúdo, a história feita no futuro. Hartog (2015, p. 138) comenta que dentro do regime moderno: “A história passou a ser essencialmente um ultimato dirigido pelo Futuro ao Contemporâneo" e "o passado é, por princípio ou por posição, ultrapassado".

François Dosse (2013) afirma que o acontecimento, o fato, hoje é feito pelas mídias, sobretudo no século XXI, mediado por um "tempo" público. "Imediatamente, a informação cola ao acontecimento a ponto de fazer parte integrante dele" (DOSSE, 2013, p.260). Para ele, o monopólio da história pertence à mídia de massa. Deste momento em diante a sociedade é atingida, sem ter como evitar, pelo acontecimento noticiado pelas mídias.

Neste sentido, o acontecimento midiático é o que se afasta da norma, que é acidental, define Dosse (2013). Por isso, esse acontecimento é selecionado pela mídia para ampla divulgação e, assim, ganha a força e dimensão que assistimos em Porto Alegre/RS. Mesmo a justiça federal solicitando que o Santander revisse sua decisão, a 
força da massificação de termos como pedofilia ou zoofilia, fez com que o banco não voltasse atrás. O cancelamento da exposição Queermuseu demonstra que hoje as ameaças à liberdade de expressão não vêm mais do Estado, mas de grupos de pressão organizados na internet.

O que talvez uma parcela de indivíduos não tenha percebido é que é possível atacar a pedofilia e a zoofilia e ao mesmo tempo defender o direito de uma exposição de arte permanecer aberta. Um raciocínio de Umberto Eco (2016) pavimenta este terreno pois para o autor é possível que, diante de uma obra de arte, as pessoas possam compreender o que ela comunica e, ainda assim, não aceitar. Isso significa que a arte não é o Absoluto, segundo ele, mas uma atividade que estabelece um diálogo com diferentes interesses, outras atividades que não somente o significado materializado da obra final.

Desprezar o raciocínio de Eco, única e simplesmente para evitar o debate, criando um comportamento monolítico, é postura inaceitável e, sobretudo, autoritária. Acontece que as pessoas nas redes sociais parecem não ter um intelecto autônomo, mas têm seu grupo, ao qual se fundem como em uma tribo, unida pelo ódio aos símbolos da tribo contrária. Nessa história do tempo presente, os liberais parecem perdidos. Assim, nota-se que nada os preparou para o novo sufocamento do indivíduo sob a voz coletiva. 


\section{Referências}

A VITÓRIA das Trevas. Veja, São Paulo, v. 2548, ano 50, n. 38, p. 74-77, 2017.

COCCHIARALE, Fernando. Quem tem medo da arte contemporânea. Recife: Massangana, 2006.

CORBIN, Alain Corbin (Orgs.). História do Corpo 3: as mutações do olhar: O século XX. In: MICHAUD, A., Visualizações: o corpo e as artes visuais. 2. ed. Petrópolis: Vozes. 2008.

DEL PRIORI, Mary. Histórias Íntimas: sexualidade e srotismo na história do Brasil. São Paulo: PLANETA, 2011.

DOSSE, François. Renascimento do acontecimento: um desafio para o historiador: entre Esfinge e Fênix. São Paulo: Editora Unesp, 2013.

ECO, Umberto. A definição da arte (1955 a 1963). Rio de Janeiro: Record, 2016.

FIDELIS, Gaudêncio (Org.). Queermuseu: cartografias da diferença da arte brasileira. São Paulo: Santander Cultural, 2017.

FIDELIS, Gaudêncio. Gaudêncio Fidelis e a polêmica da arte. [Entrevista cedida a] Ivan Mattos. Bá, Porto Alegre, RS, n. 24, p. 38-41, 2018.

FOSTER, Gustavo. "Queermuseu”: quais são e o que representam as obras que causaram o fechamento da exposição. Gaúcha ZH, Porto Alegre, set. 2017. Seção Artes. Disponível em: <https:/gauchazh.clicrbs.com.br/cultura-e-lazer/artes/noticia/2017/og/queermuseuquais-sao-e-o-que-representam-as-obras-que-causaram-o-fechamento-da-exposicao9894305.html>. Acesso em 15 set. 2017.

HARTOG, François. Regime de historicidade: presentismo e experiências do tempo. 1. ed. Belo Horizonte: Autêntica, 2015.

HEIDEGGER, M. A origem da obra de arte (1936). Lisboa: Edições 70, 1999.

LARROSA, Jorge. A operação ensaio: sobre o ensaiar e o ensaiar-se no pensamento, na escrita e na vida. Educação \& Realidade [dossiê Michel Foucault], Porto Alegre, v. 29, n.1, 2004 .

MEDEIROS, Luiz Guilherme. Caso Santander - Queermuseum: o boicote como resposta liberal. Huffpost, Rio de Janeiro, set. 2017. Seção Opinião. Disponível em: <https://www.huffpostbrasil.com/luiz-guilherme-medeiros/caso-santanderqueermuseum-o-boicote-como-resposta-liberal_a_23206492/>. Acesso em 12 set. 2017. 
MOVIMENTO BRASIL LIVRE (MBL). São Paulo, 2014. Disponível em:

<http://www.mbl.org.br >. Acesso em: 01 dez. 2017.

RAMALHO E OLIVEIRA, Sandra. Imagem também se Lê. 2. ed. São Paulo: Rosari, 2009.

REMOND, Rene. Introdução a história do nosso tempo. Lisboa: Gradiva, 1994.

RIOUX, Jean-Pierre. Pode-se fazer uma história do presente? In: CHAUVEAU, A., TÉTART, P. (Orgs.). Questões para a história do presente. Bauru, SP: EDUSC, 1999.

ZERNER, Henri (Orgs.). História do Corpo Vol. 2: da revolução a grande guerra. Petropolis, RJ: Vozes. 2005. 